\title{
Deformation and Fracture Behavior of Rapidly Solidified and Annealed Iron-Silicon Alloys
}

\begin{abstract}
J.E. WITTIG and G. FROMMEYER
In this study, the mechanical properties, deformation behavior, and fracture modes of ironsilicon melt-spun ribbons are related to changes in silicon composition from 4.5 to $6.5 \mathrm{wt}$ pct and the influence of ordering phase transformations. The as-solidified melt-spun ribbons, which exhibit plasticity even for the Fe-6.5 wt pet Si composition, provide the opportunity to characterize dislocation glide. Tensile deformation with a plastic strain of $\sim 2$ pct produced planar slip of pure edge and pure screw mainly on $\{112\}$ slip planes although slip on $\{011\}$ and $\{123\}$ planes was also observed. The extended dislocations became qualitatively more planar as silicon concentration increased owing to reduced cross-slip. For the Fe-6.5 wt pct Si material, pairs of dislocations with the same Burgers vector were observed. As ribbon thickness increased, the material's ductility decreased. Thinner ribbons provide a reduced mean free path of gliding dislocations and fewer impediments to glide before they reach the ribbon surface, which removes strain hardening effects. In the as-solidified state, the $\mathrm{B} 2$ and $\mathrm{DO}_{3}$ order has been suppressed. Heat treating the $6.5 \mathrm{wt}$ pct silicon ribbons induces the ordering phase transformations and reduces the ductility. The most embrittled condition occurs for the coexistence of $\mathrm{B} 2$ and $\mathrm{D} 0_{3}$ ordered domains after annealing at $400{ }^{\circ} \mathrm{C}$ to $500{ }^{\circ} \mathrm{C}$.
\end{abstract}

DOI: $10.1007 / \mathrm{s} 11661-007-9436-7$

(C) The Minerals, Metals \& Materials Society and ASM International 2008

\section{INTRODUCTION}

\section{A. Effect of Silicon on the Magnetic Behavior of Iron}

ALLOYS of iron and silicon are technologically important owing to their combination of superior soft magnetic properties and relative low cost. ${ }^{[1]}$ Most common grades of electrical steel contain about 3 wt pct $\mathrm{Si}$ and are available in both nonoriented and oriented states. In the oriented condition, a series of thermomechanical processes are required to produce the preferred crystallographic cube on edge texture with the easiest direction of magnetization, $\langle 001\rangle$, appropriately aligned for the application. The worldwide steel industry produces over 1 million tons of grain oriented, "Goss textured," ironsilicon sheet each year. Improving the production methods is an ongoing process. ${ }^{[2]}$ The ideal soft magnetic material must have high magnetic permeability and induction while minimizing core losses from eddy currents and hysteresis during cyclic magnetization. Raising the silicon content in iron causes a decrease in the saturation induction, but this is of minor consequence compared to the beneficial effects of higher permeability, lower magnetostriction, and reduced core losses from a combination of lower intrinsic coercivity and increased resistivity. A composition of approximately $6.5 \mathrm{wt} \mathrm{pct}$

J.E. WITTIG, Associate Professor of Materials Science and Engineering, is with the Electrical Engineering and Computer Science Department, Vanderbilt University, Nashville, TN 37235. Contact e-mail: j.wittig@vanderbilt.edu G. FROMMEYER, Department Head and Scientific Board Member, is with the Department of Materials Technology, Max-Planck-Institute for Iron Research (or Eisenforschung), 40237 Duesseldorf, Germany.

Manuscript submitted June 12, 2006.

Article published online January 3, 2008 silicon is reported to achieve the optimum soft magnetic properties with a maximum in permeability, a minimum in coercivity, and a zero $\langle 001\rangle$ magnetostriction coefficient for noise free power transmission. ${ }^{[1]}$ Unfortunately, accompanying these improved soft magnetic properties is a drastic decrease in ductility at about 4 to 5 wt pct Si, which prohibits conventional processing, specifically cold rolling of high silicon-containing alloys. ${ }^{[3]}$ Concomitant with the change in the room temperature fracture behavior with increasing silicon content are $\mathrm{B} 2$ and $\mathrm{D} 0_{3}$ superlattice phase transformations occurring at silicon composition higher than $5 \mathrm{wt}$ pct $(9.5$ at. pct $) .{ }^{[4]}$ The influence of atomic order on the electrical and magnetic properties is still an active area of research.$^{[5,6]}$

\section{B. Plastic Deformation of $\mathrm{B} 2$ and $\mathrm{DO}_{3}$ Ordered Structures}

Although the ordering phenomena in high silicon electrical steel has recently been studied by Mössbauer spectroscopy and neutron diffraction, ${ }^{[7-9]}$ transmission electron microscopy (TEM) offers the advantage that in addition to superlattice reflections in electron diffraction patterns, dark-field (DF) imaging reveals the distribution of ordered domains and the presence of antiphase domain boundaries. ${ }^{[4]}$ Electrons also scatter more strongly than X-rays or neutrons, which make the TEM investigations more sensitive to the onset of atomic order. The equilibrium B2 and phase boundaries determined by TEM are shown in Figure 1 in the ironrich section of the iron-silicon binary phase diagram. ${ }^{[4]}$ Figure 2 shows schematic representations of the B2 and $\mathrm{D}_{3}$ superlattices. The $\mathrm{B} 2$ structure $(P m 3 m)$ having the formula $\mathrm{AB}$ can be described by a simple cubic lattice 


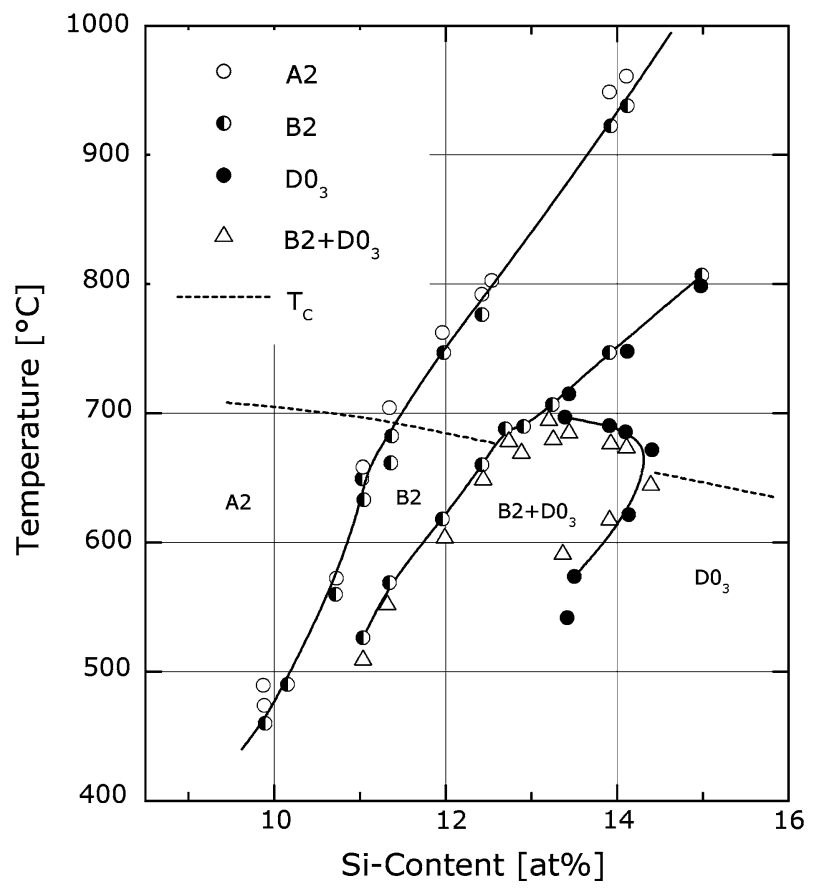

Fig. 1-Experimental data from Ref. 4 that reveal the equilibrium phase boundaries of the $\mathrm{B} 2$ and $\mathrm{D}_{3}$ ordered phases in the iron-silicon system determined by TEM investigations.

with two atoms per unit cell, an $\mathrm{A}$ atom at $0,0,0$ and a $\mathrm{B}$ atom at $1 / 2,1 / 2,1 / 2$. Each A-type atom is coordinated with eight B-type atoms and each $\mathrm{B}$ atom with eight $\mathrm{A}$ atoms (i.e., all unlike nearest neighbors). The description of the $\mathrm{D}_{3}$ structure $(F m 3 m), \mathrm{A}_{3} \mathrm{~B}$, requires eight body-centered-cubic (bcc) unit cells $\left(a_{o}^{\prime}=2 a_{o}\right)$ with B atoms occupying four of the body centers, $1 / 4,1 / 4,1 / 4$, $3 / 4,3 / 4,1 / 4,1 / 4,3 / 4,3 / 4$, and $3 / 4,1 / 4,3 / 4$, so that each B-type atom has A-type atoms for both nearest and next-nearest neighbors. Because superlattice formation in the ironsilicon system occurs for alloys that are far from the stoichiometry required for perfect order, the silicon atoms are considered to be randomly positioned on their superlattice positions with iron atoms filling those unoccupied sites. Thus, an alloy of Fe-6.5 wt pet (12.15 at. pct) Si has only 24 pet of the silicon atoms required for perfect $\mathrm{B} 2$ order and 49 pct for the $\mathrm{D} 0_{3}$ structure.

A B2 ordered structure, which prevents nearest neighbor bonds between like atoms, will form in a bcc (A2) substitutional solid solution of elements A and B when

$$
E_{a a}+E_{b b}>2 E_{a b}
$$

where $E_{a a}, E_{b b}$, and $E_{a b}$ are the bond energies for AA, $\mathrm{BB}$, and $\mathrm{AB}$ bonds. The passage of a dislocation with Burgers vector $\mathbf{a} / 2\langle 111\rangle$ in the $\mathrm{B} 2$ structure disturbs the ordered arrangement by bringing like atoms into contact. Dislocation glide effectively creates an antiphase domain boundary (APB) on the slip plane with an increase in energy proportional to the APB interfacial energy, $G$. Using a method derived by Flinn, ${ }^{[10]}$ Marcinkowski, and Fisher ${ }^{[11]}$ shows that for any slip

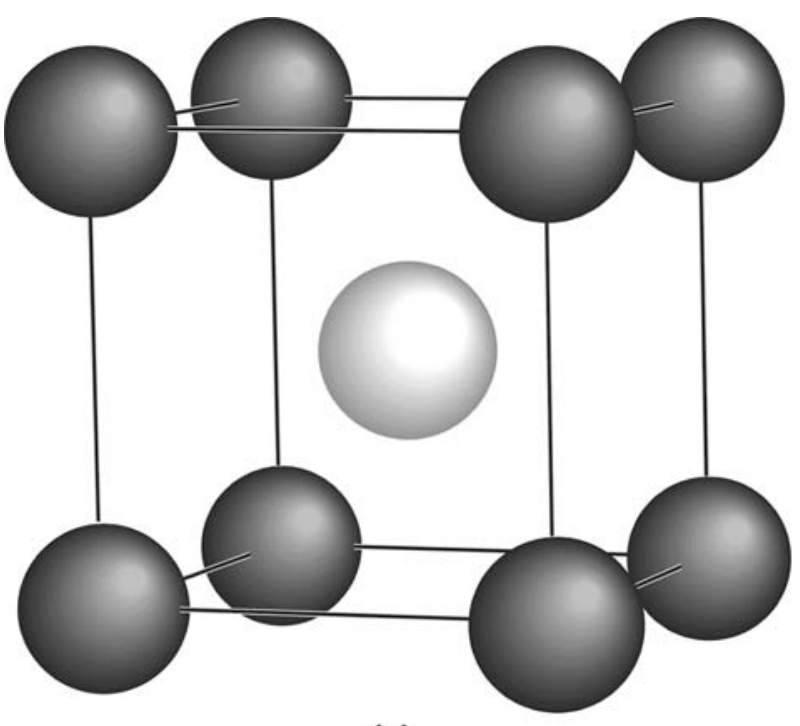

(a)

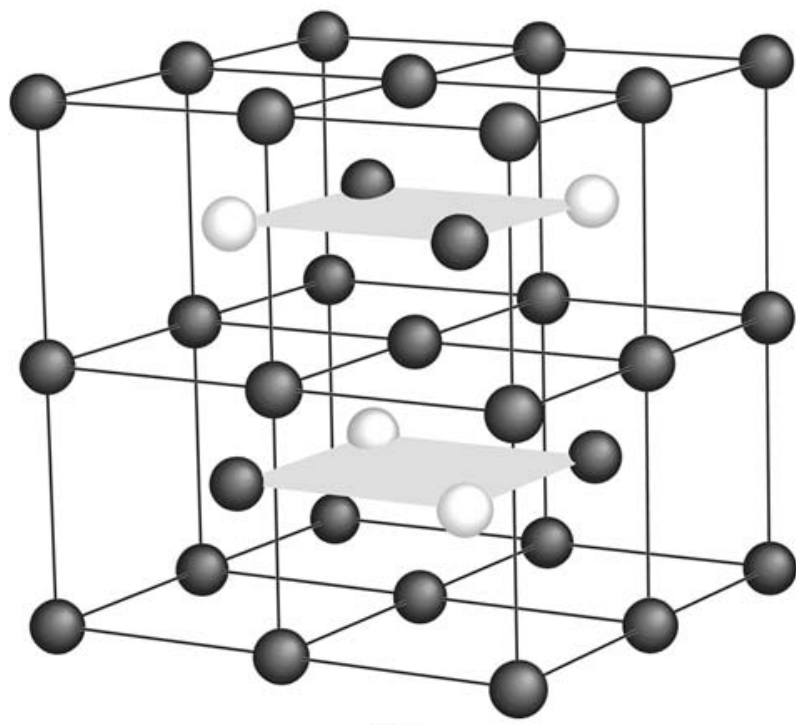

(b)

Fig. 2-Schematic diagrams of the $(a) \mathrm{B} 2$ and $(b) \mathrm{D}_{3}$ unit cells.

plane in the $\langle 111\rangle$ zone, the APB interfacial energy is quantified by

$$
G^{\mathrm{APB}}=2 h E / a^{2}(N)^{1 / 2}
$$

with $(h>k>1)$, where $E=E_{a a}+E_{b b}-2 E_{a b}$ and $N=h^{2}+k^{2}+l^{2}$.

Because slip of a second dislocation on the same plane would reorder the B2 superlattice, the APB interfacial energy would be removed. Thus, a pair of dislocations, a superlattice dislocation having a net Burgers vector of $\mathbf{a}\langle 111\rangle$, is predicted to move through the lattice at a lower stress compared to single dislocations. ${ }^{[12]}$ Although superlattice dislocations would be energetically favorable, this complicated arrangement of dislocations would be expected to severely limit dislocation cross-slip and inhibit accommodation of plastic deformation. 
Marcinkowski and Brown have described the crystallographic configuration of superlattice dislocations in the $\mathrm{D}_{3}$ superlattice. ${ }^{[13]}$ Ordinary dislocations in the expanded $\mathrm{D}_{3}$ unit cell $\left(a_{o}{ }^{\prime}=2 a_{o}\right)$, have Burgers vectors $\mathbf{a}^{\prime} / 4\langle 111\rangle$. For the $\mathrm{D}_{3}$ superlattice of type $\mathrm{A}_{3} \mathrm{~B}$, where $\mathrm{B}$ atoms have both first and second unlike nearest neighbors, the passage of four ordinary dislocations with $\mathbf{b}=\mathbf{a}^{\prime} / 4\langle 111\rangle$ is required to completely reorder the lattice. Slip of an ordinary dislocation on a $\{110\}$ plane produces an APB by changing both first and second nearest neighbors. Although a second ordinary dislocation reorders first nearest neighbors with a reduction in APB energy, second nearest neighbors remain disordered. A third ordinary dislocation again disorders nearest neighbors raising the APB energy, and finally, a fourth dislocation transforms the lattice back to the initial state. Because the APB energy between dislocations 2 and 3 is relatively low compared to the APB energy between dislocations $1-2$ and 3-4, the two dislocation pairs would not be strongly connected.

Superlattice dislocations were first experimentally observed with TEM by Marcinkowski et al. in the $\mathrm{Cu}_{3} \mathrm{Au}, \mathrm{L1}_{2}$ superlattice based on the face-centeredcubic (fcc) structure. ${ }^{[14,15]}$ Because perfect dislocations in an fcc structure with low stacking fault energy tend to split into partials, the superlattice dislocation configuration for the $\mathrm{Cu}_{3} \mathrm{Au}$ structure consists of two pairs of partial dislocations held together by an antiphase domain boundary. However, in $\mathrm{B} 2$ and $\mathrm{D}_{3}$ structures, superlattice dislocations are not always observed. Experimental evidence from stoichiometric $\mathrm{Fe}_{3} \mathrm{Al}$ alloys, which exhibit both $\mathrm{B} 2$ and $\mathrm{D}_{3}$ order, suggests that dislocations move at room temperature as ordinary a/2 2111$\rangle$ types. $^{[13]}$ Superlattice dislocations have only been detected in deformed $\mathrm{D}_{3}$-ordered $\mathrm{Fe}_{3} \mathrm{Al}$ at specific elevated temperatures ${ }^{[16]}$ or in nonstoichiometric $\mathrm{Fe}_{3} \mathrm{Al}$ (Fe-31 at. pct Al). ${ }^{[17]}$ The lack of superlattice dislocations in $\mathrm{Fe}_{3} \mathrm{Al}$ has been accounted for by the relatively low APB energy present in the ordered $\mathrm{Fe}_{3} \mathrm{Al}$ lattice. ${ }^{[13]}$ However, a theoretical analysis predicts that the APD energy in $\mathrm{Fe}_{3} \mathrm{Si}$ is at least twice as large as for the $\mathrm{Fe}_{3} \mathrm{Al}$ superlattice, which would increase the probability for the existence of superlattice dislocations in the $\mathrm{D}_{3}$ superlattice of $\mathrm{Fe}_{3} \mathrm{Si}^{[13]}$

Limited experimental work has been performed on the dislocation configurations in iron-silicon alloys owing to the completely brittle behavior with increased silicon content. The most extensive experimental data set for dislocation slip in iron-silicon alloys stems from a study of slip traces by Barrett et al. on alloys with silicon levels from 1 to $5 \mathrm{wt}$ pct at temperatures ranging from $-200{ }^{\circ} \mathrm{C}$ to $25^{\circ} \mathrm{C}$. ${ }^{[18]}$ The crystallographic mechanism of slip was characterized by three composition ranges as follows: 0 to 1 wt pet $\mathrm{Si}$, with slip on $\{110\},\{112\}$, and $\{123\}$ planes at all temperatures studied; 1 to 4 wt pct Si, with slip at low temperatures on only $\{110\}$ planes, and at higher temperatures on $\{112\}$ and $\{123\}$ planes as well; and 4 to 5 wt pet $\mathrm{Si}$, with slip on $\{110\}$ planes at all temperatures studied. A definite change in the morphology of the slip lines at room temperature was observed at silicon levels higher than 4 wt pct ( 7.6 at. pct). Silicon concentrations of less than 4 wt pct exhibited wavy slip whereas in alloys with 4 wt pct and more, the slip lines were perfectly straight.

Saburi and Nenno ${ }^{[19]}$ have performed a TEM study of the antiphase domain structures and the dislocation configurations in an alloy of 13 at. pet Si. Mechanical deformation was achieved by a single cold rolling pass with minimal reduction in thickness. A TEM experiment has the advantage of direct observation of both the dislocation lines as well as the APBs by using DF imaging techniques with superlattice diffraction vectors. The experimental evidence showed that dislocations in the $\mathrm{DO}_{3}$ superlattice moved as pairs of ordinary dislocations bound together by an APB. Superlattice dislocation configurations with four ordinary dislocations were not observed. Contrary to the experimental evidence of Barrett et al. where dislocation slip was restricted to $\{110\}$ planes, Saburi and Nenno reported dislocations and the deformation-induced APB to lie in $\{110\},\{112\}$, or $\{123\}$ planes.

\section{Rapid Solidification by Melt Spinning}

Many investigators have studied rapidly solidified iron-silicon alloys produced by planar flow casting melt spinning. ${ }^{[20-24]}$ Ribbons with higher silicon content (e.g., $6.5 \mathrm{wt}$ pct $\mathrm{Si}$ ) and improved magnetic properties are formed directly from the melt, which is advantageous because conventional thermomechanical treatment is unable to process this brittle alloy. An interesting result is that melt-spun ribbons of $6.5 \mathrm{wt}$ pct $\mathrm{Si}$ with thickness less than $50 \mu \mathrm{m}$ actually exhibited ductility, as shown by simple bend tests. ${ }^{[20]}$ However, ribbons thicker than $50 \mu \mathrm{m}$ were always brittle and fracture when bent. ${ }^{[20]}$ Microstructural characterization of these ribbons from alloys with 6.3 to $6.5 \mathrm{wt}$ pet $\mathrm{Si}$ have shown that melt spinning has significantly suppressed the $\mathrm{D}_{3}$ transformation, whereas the B2 superlattice structure is always present to a limited degree. ${ }^{21]}$ A reduction in the degree of chemical ordering could translate into an increase in ductility by easier dislocation slip.

In the current work, the mechanical properties, deformation behavior, and fracture mode of iron-silicon melt-spun ribbons with thicknesses from 20 to $120 \mu \mathrm{m}$ and compositions ranging from 4.5 to $6.5 \mathrm{wt}$ pet Si have been studied. Using TEM to analyze the ordering phase transformations and dislocation configurations after plastic deformation, the mechanism responsible for the change in ductility of iron-silicon melt-spun ribbons with increasing silicon content and ribbon thickness is elucidated. The decrease in ductility with increasing silicon content and ribbon thickness can be explained by characterization of the solidification structure, the ordering phase transformations, and dislocation configurations.

\section{EXPERIMENTAL PROCEDURE}

Alloys with silicon content ranging from 4.5 to 6.5 wt pct were prepared from electrolytic iron 99.98 pct and high-purity silicon 99.999 pet by induction melting. Rapidly solidified ribbons were processed using a 
computer-controlled melt spinning apparatus equipped with infrared (IR) pyrometers for cooling rate measurements. The details of this apparatus are described elsewhere. ${ }^{[23]}$ The iron-silicon ribbons were cast in air on a mild steel wheel with a helium protective gas at the melt puddle. Final cooling was achieved either by air cooling or by quenching in a water bath after the ribbon separated from the melt spinning wheel. The ribbons were $2 \mathrm{~cm}$ in width and ranged in thickness from 20 to $120 \mu \mathrm{m}$. The silicon composition of the ribbons, measured by wet chemistry, varied typically by $\pm 0.5 \mathrm{wt}$ pct $\mathrm{Si}$ from the nominal composition. However, for the composition near $6.5 \mathrm{wt}$ pct $\mathrm{Si}$, more than one ingot was used in this study, so the mechanical property data for this composition were taken from samples with composition range of $6.4 \pm 0.1$ wt pet Si. Typical carbon content was $0.04 \mathrm{wt}$ pct and nitrogen levels were $\sim 100 \mathrm{ppm}$. Oxygen measurements from the ribbons were not considered meaningful because the surface oxide would dominate over the internal oxygen content. As-solidified ribbons were also heat treated in evacuated quartz ampules to study the influence of ordering phase transformations on the mechanical properties. The ampules were air cooled from the annealing temperature to room temperature.

The mechanical behavior of the ribbons was characterized using microhardness measurements, bend tests, and tensile testing. Microhardness was measured by using a Vickers indenter with a 25 pond load applied for 30 seconds on transverse cross-sectional samples mounted in thermosetting resin. The size of the indentations was always less than 20 pct of the total crosssectional thickness of the ribbon to ensure that surface relaxation effects did not influence the results. Bend testing is a simple method to characterize the ductility of melt-spun ribbons. In this study, a fixture with two blocks having $0.1-\mathrm{mm}$ radii edges was used to clamp the ribbons. A bend number, $B_{n}$, was determined by counting the number of cycles that the ribbon could be bent $180 \mathrm{deg}$ from one side to the other until fracture (the first $90 \mathrm{deg}$ of bending counted as 1/2). For example, if the ribbon would fracture upon bending from the initial vertical position to a $90 \mathrm{deg}$ angle, then $B_{n}=0.5$, if the ribbon would not fail until it was returned to the upright position, $B_{n}=1.0$, another $90 \mathrm{deg}$ to the opposite side, $B_{n}=1.5$, and so on.

The ribbons were also tested in uniaxial tension to determine the yield strength, ultimate tensile strength, and elongation to failure. Tensile samples were prepared by cutting a $60-\mathrm{mm}$ gage length in the thin ribbons by using a standard tensile coupon as a template. The gage length edges were finished by grinding with 240-grit $\mathrm{SiC}$ paper while the thin ribbon was clamped between the two standard tensile bars. These samples were tested to failure in uniaxial tension at a strain rate of $8 \times 10^{-5} \mathrm{~s}^{-1}$. Elongation was measured by a clip gauge extensometer and load was converted into engineering stress by using an average cross-sectional area. Although the width of the gage length is essentially constant, the ribbon surfaces, especially the top surface, have irregularities with variations in the cross-sectional thickness in individual areas of $\sim 20$ pct. Therefore, the average thickness was determined by measuring the density using a gas pycnometer.

Microstructural characterization of the ribbons was performed by using a combination of optical microscopy, X-ray diffraction, scanning electron microscopy (SEM), Auger electron spectroscopy (AES), and transmission electron microscopy (TEM). Samples for TEM were prepared from the ribbons by punching 3-mmdiameter discs and twin-jet electropolishing in 18 vol pct perchloric acid, 18 vol pct 2-butoxyethanol, and $64 \mathrm{vol}$ pet glacial acetic acid at $28 \mathrm{~V}$ and $0{ }^{\circ} \mathrm{C}$ until multiple perforations were produced. Continued electropolishing after the initial perforation was necessary owing to the uneven ribbon thickness. Also foils were prepared by selective electropolishing from only one side to observe the microstructures near the contact and top surfaces. The thinned foils were examined with PHILIPS (Holland) EM420T and CM20T microscopes to characterize the defect densities, precipitate distributions, and the $\mathrm{B} 2$ and $\mathrm{D}_{3}$ superlattices. The $\{110\}$ zone axis was always used to investigate the presence of chemical ordering because both the $\mathrm{B} 2$ and $\mathrm{D}_{3}$ superlattice reflections appear in this orientation.

\section{RESULTS}

\section{A. Solidification Structure}

Optical microscopy of the ribbons revealed the solidification structure was independent of silicon content for this range in compositions. However, processing parameters that influenced the cooling rate, such as wheel speed, heat transfer between ribbon and wheel, and contact length before ribbon-wheel separation, determined the final ribbon thickness and structure. The optical micrograph in Figure 3 shows a representative longitudinal cross section from a ribbon with good thermal contact during melt spinning. Small equiaxed grains often formed at the contact surface-in the chill zone of the ribbon-while the typical grain morphology was columnar grains tilted slightly toward the casting direction. The size and distribution of these crystallites were determined by the cooling conditions.

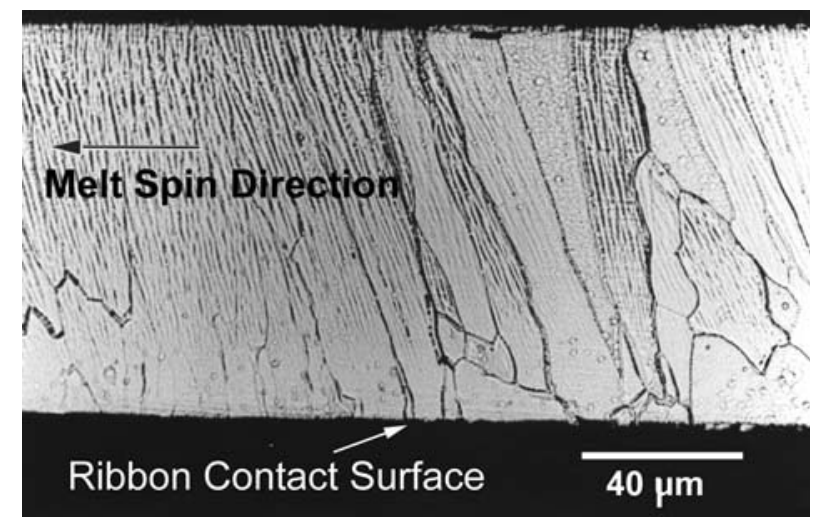

Fig. 3-Optical micrograph of the cross section of an iron-silicon melt-spun ribbon. The columnar grains are tilted in the melt spinning direction. 


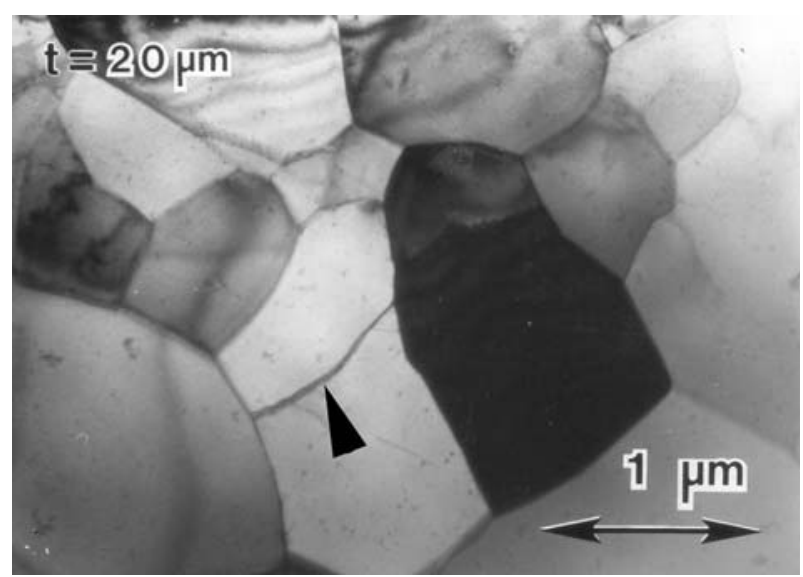

Fig. 4-TEM BF image of the melt-spun microstructure viewed normal to the ribbon surface showing the equiaxed grain structure. The arrowhead indicates an example of a low-angle grain boundary. The small dark round features in this grain are silicon oxide particles, typically, $\sim 25 \mathrm{~nm}$ in diameter.

Increasing ribbon thickness corresponds to a lower cooling rate (determined from the pyrometer measurements on the top surface of the ribbons) and a larger average grain size (measured normal to the ribbon surface). For cooling rates of $10^{6} \mathrm{~K} / \mathrm{s}$, the typical grain size was less than $10 \mu \mathrm{m}$ while for lower cooling rates, of $10^{5} \mathrm{~K} / \mathrm{s}$, the grain size increased to 20 to $30 \mu \mathrm{m}$.

Figure 4 is a typical bright-field (BF) TEM image from a $20-\mu \mathrm{m}$-thick ribbon of the melt-spun microstructure as observed in thin foils viewed normal to the ribbon surface. Equiaxed grains often contained lowangle grain boundaries and small precipitates located within the grain interiors. The precipitates, typically $\sim 25 \mathrm{~nm}$ in diameter, were identified as silicon oxides with thin-window energy dispersive X-ray spectroscopy. The oxide volume fraction was the largest in the thinnest ribbons and decreased with ribbon thickness. Thicker ribbons had fewer oxides in the central section with larger amounts observed in regions close to the outer surfaces as observed in foils selectively electropolished from one side. Dislocation density varied from sample to sample and ranged from virtually dislocation free grains to relatively high levels. This variation in the dislocation density could be explained by unequal deformation for different portions in a ribbon, which is produced after leaving the spinning wheel at velocities of more than $20 \mathrm{~m} / \mathrm{s}$. These dislocations, which formed at elevated temperatures in the as-solidified ribbons, were randomly distributed with the dislocation lines having curved morphologies.

\section{B. Texture Determination}

The as-solidified ribbons revealed a strong preferred orientation of the $\{001\}$ planes parallel to the ribbon surface. Pole figures from the melt-spun ribbons exhibit a maximum intensity for the $\{002\}$ pole at four times random that is tilted approximately $20 \mathrm{deg}$ from the ribbon surface normal. The $\{002\}$ preferred orientation corresponds to the inclination of the columnar grains observed in Figure 3. Annealing the ribbons at temperatures higher than $1000{ }^{\circ} \mathrm{C}$, where grain growth occurs intensified this texture and the $\{002\}$ pole normal to the ribbon surface for a ribbon annealed at $1100{ }^{\circ} \mathrm{C}$ for 1 hour increases to eight times random. The distribution of orthogonal $\{020\}$ and $\{200\}$ poles indicates that the $\{110\}$ direction also has a preferred orientation along the longitudinal axis of the ribbon. These results are in agreement with previous investigations on the textures in iron-silicon melt-spun ribbons. ${ }^{[20]}$

\section{Ordering Phase Transformation}

Samples from the as-received materials (induction melted and cast) and the melt-spun ribbons (as solidified and heat treated) were compared for evidence of the B2 and $\mathrm{D}_{3}$-ordered phases from [110] zone axis electron diffraction patterns (e.g., Figure 5(b)) and DF images formed from the $\mathrm{B} 2$ and $\mathrm{D}_{3}$ superlattice reflections. These results are categorized in the following way:

Category $1-$ No observable intensity in the diffraction pattern of the superlattice reflection (i.e., no evidence of chemical order).

Category 2-Faint diffracted intensity of the superlattice reflection but inadequate to be observed in a DF image.

Category 3-Strong diffracted superlattice intensity but incomplete ordering (observed as small isolated regions of bright contrast in a DF image).

Category 4-Complete ordering where the individual domains impinge creating APBs.

Category 1 indicates that the amount of ordering of the silicon atoms in the iron lattice is less than that required to be observed in a selected area electron diffraction pattern. However, chemical order may still be present, which requires more sensitive methods (e.g., atomic layer resolution, atom probe field ion microscopy (APFIM)) for detection. Examples for category 1 are the melt-spun Fe-5.0 wt pet $\mathrm{Si}$ ribbons and the as-cast Fe-4.5 wt pet Si alloy.

Category 2 is a qualitative estimate of the amount and degree of ordering. In many cases, superlattice reflections could not be observed on the phosphor screen of the TEM but were only detectable in highly overexposed photographs of the electron diffraction pattern. For the highest sensitivity, the thinnest regions of the foil were selected in order to minimize the diffuse background intensity in the diffraction pattern from inelastic scattering. However, even when the superlattice intensity could be faintly detected on the screen, this amount of order was inadequate to be observed in a DF image, even in 50-second exposures. Examples of this condition are the $\mathrm{B} 2$ reflections from the as-cast Fe-5.0 wt pet $\mathrm{Si}$ alloy and the melt-spun Fe-5.5 wt pet Si ribbons; the $\mathrm{DO}_{3}$ reflections for the as-cast Fe-5.5 wt pet $\mathrm{Si}$ alloys and the Fe-6.4 wt pet silicon ribbons.

Category 3 requires that ordered domains be observed in a DF image. For the melt-spun ribbons this often indicates that the ordering transformation has been suppressed and represents a wide range in the degree of order. All of the melt-spun ribbons with $6.4 \mathrm{wt}$ pct 
silicon show various volume fraction of B2 ordered material that is largely dependent on the cooling conditions after the ribbon has separated from the melt spinning wheel. Figure 5(a) shows category 3 ordering from a ribbon of Fe-6.4 wt pet $\mathrm{Si}$ after the melt spinning process. The amount of B2 order also varied from the outer surfaces to the center of the ribbon.

Category 4 was only observed in ribbons that were heat treated or in the as-received materials where the equilibrium phase diagram predicts an ordered phase.
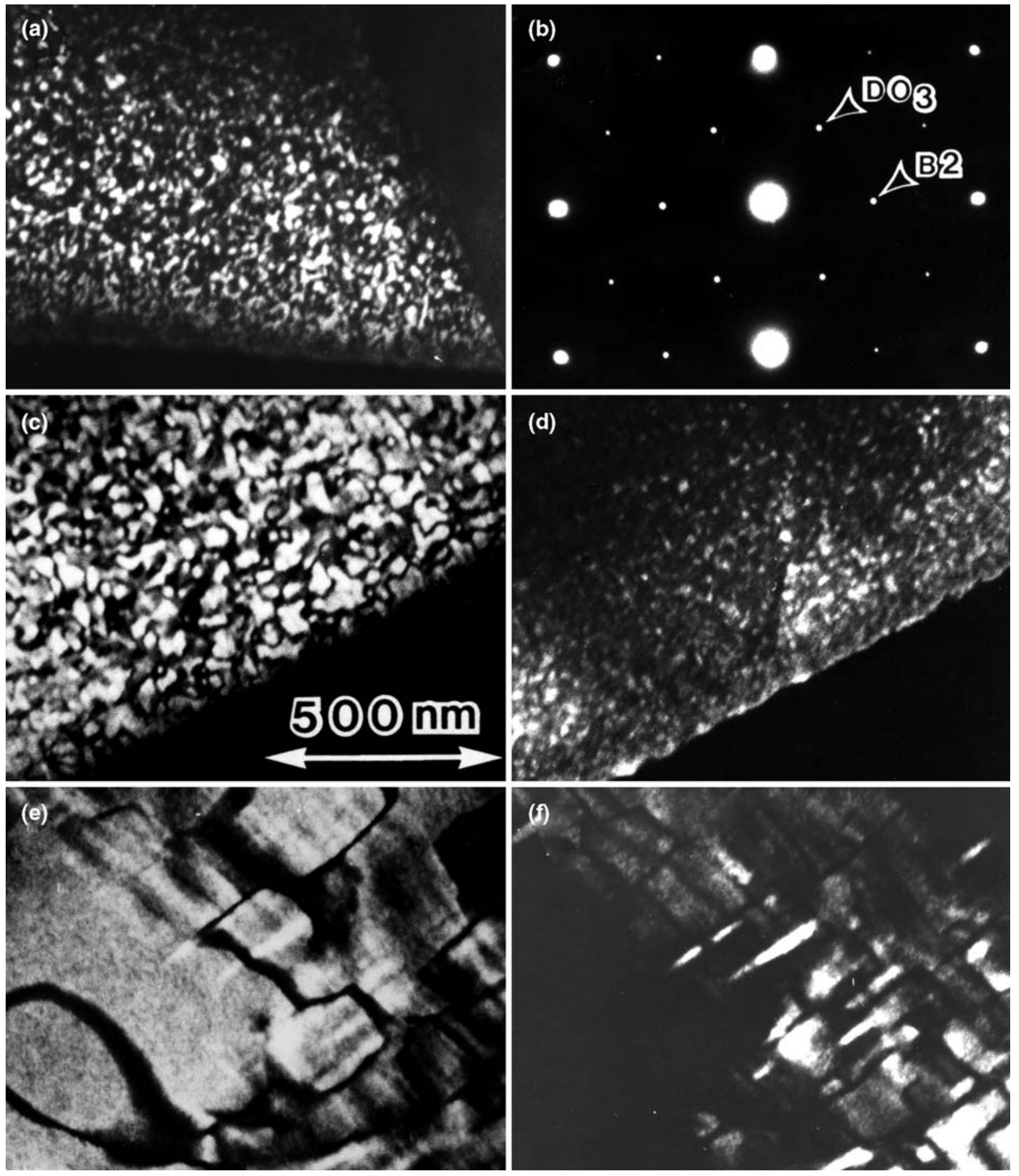

Fig. 5-DF images from the Fe-6.4 wt pet $\mathrm{Si}$ ribbons in the as-solidified state and after annealing reveal $\mathrm{B} 2$ and $\mathrm{D} 0_{3}$ ordering in the microstructure. (a) The DF image using a B2 reflection from the [110] zone axis of the as-solidified microstructure from a 30- $\mu \mathrm{m}$-thick ribbon exhibits a partially ordered state. $(b)$ The [110] iron-silicon zone axis from a heat-treated ribbon contains both $\mathrm{B} 2$ and $\mathrm{D} 0_{3}$ superlattice spots. $(c)$ and $(d)$ After annealing, the $6.4 \mathrm{wt}$ pct silicon ribbon at $500^{\circ} \mathrm{C}$ for $24 \mathrm{~h}$; the DF image in (c) shows that the B2 ordered domains have enlarged, while the DF image in (d) depicts the isolated $\mathrm{D}_{3}$ ordered regions. $(e)$ and $(f)$ Annealing for $24 \mathrm{~h}$ at $600{ }^{\circ} \mathrm{C}$ produces completely $\mathrm{B} 2$ ordered regions in (e) and $\mathrm{D}_{3}$ ordered areas in (f). 
The DF images in Figures 5(c) and (d) display the ordered structure of a $\mathrm{Fe}-6.4 \mathrm{wt}$ pct $\mathrm{Si}$ ribbon annealed at $500{ }^{\circ} \mathrm{C}$ for 24 hours where the distribution of B2 domains are classified into category 4 and $\mathrm{D}_{3}$ domains are category 3. Figures 5(e) and (f) show the same ribbon annealed at $600{ }^{\circ} \mathrm{C}$. This procedure produces a two-phase microstructure with examples of both B2 and $\mathrm{D}_{3}$ domains in a category 4 state.

\section{Microhardness Testing}

Figure 6(a) summarizes the microhardness data as a function of the silicon content and Figure 6(b), the changes in microhardness for ribbons with Fe-6.4 wt pet $\mathrm{Si}$ after annealing for 24 hours at various temperatures. Owing to the requirement that the indentations must be less than 20 pct of the ribbon cross-sectional thickness, the low load (25 p) and corresponding small indentations produced rather large experimental scatter. Raising the silicon level has a strong influence on the hardness. Changing the silicon concentration by only

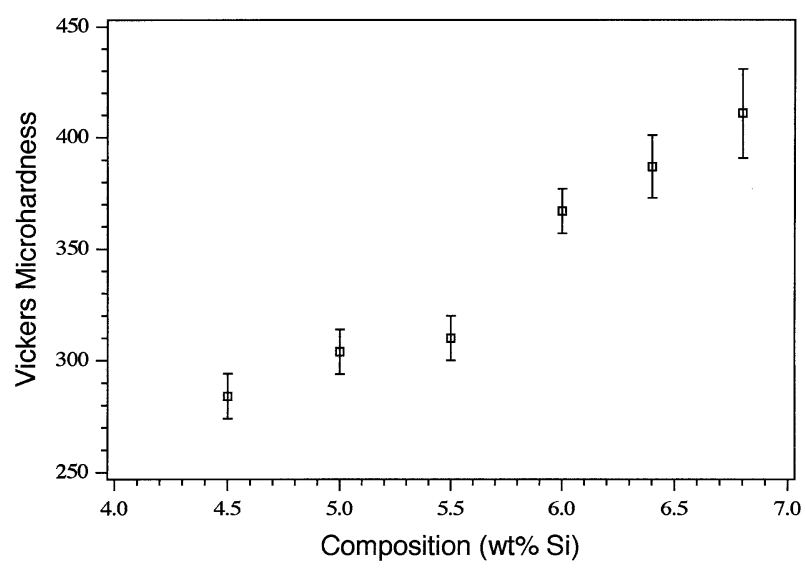

(a)

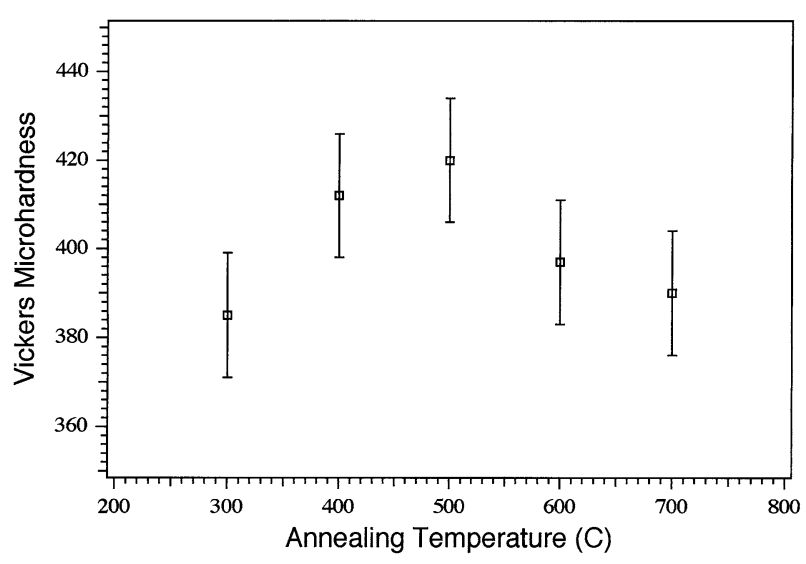

(b)

Fig. 6-(a) The Vickers microhardness data of the melt-spun ironsilicon ribbons show a large increase in hardness with increasing silicon content. These microhardness data were independent of ribbon thickness. (b) Annealing a Fe-6.4 wt pct Si ribbon for $24 \mathrm{~h}$ produces the $\mathrm{B} 2$ and $\mathrm{D}_{3}$ ordering phase transformations and corresponding changes in the microhardness.
$2 \mathrm{wt}$ pet from 4.5 to $6.5 \mathrm{wt}$ pet produces in a $40 \mathrm{pct}$ increase in hardness. This silicon composition range corresponds to increasing B2 order with the beginning of $\mathrm{DO}_{3}$ symmetry in the ribbons. However, the microhardness was independent of ribbon thickness. The microhardness values of ribbons with Fe-6.4 wt pet $\mathrm{Si}$ do not show a significant change for ribbon thicknesses ranging from 20 to $86 \mu \mathrm{m}$.

Annealing the rapidly solidified Fe-6.4 wt pet $\mathrm{Si}$ ribbons also resulted in microhardness changes. Figure 6(b) reports the Vickers microhardness after 24 hours annealing treatments of a $37-\mu \mathrm{m}$-thick ribbon. Significant increases in microhardness resulted after annealing at $400{ }^{\circ} \mathrm{C}$ to $500{ }^{\circ} \mathrm{C}$. The microstructure responsible for this enhanced hardness is shown in Figures $5(\mathrm{c})$ and $(\mathrm{d})$ as a mixed $\mathrm{B} 2-\mathrm{DO}_{3}$ superstructure. Annealing at $600{ }^{\circ} \mathrm{C}$, which produced the two-phase B2$\mathrm{DO}_{3}$ structure shown in Figures 5(e) and (f) with larger ordered domains compared to Figures 5(c) and (d), exhibited a microhardness only slightly greater than the rapidly solidified condition. At $700{ }^{\circ} \mathrm{C}$, the Fe-6.4 wt pet $\mathrm{Si}$ composition lies in the B2 single-phase field and the hardness is essentially equivalent to the as-solidified melt-spun condition.

\section{E. Bend Tests}

Bend testing allows the rapid qualitative characterization of the ribbon ductility. This test provides reproducible results where the variation in the bend number $\left(B_{n}\right)$ for a particular ribbon is typically \pm 0.5 or less. Figure 7(a) presents bent test results for three nominal compositions at various ribbon thicknesses. Because bend tests are actually low-cycle fatigue tests, ribbon thickness strongly influences $B_{n}$ owing to a greater outer fiber tensile stress and plastic strain as the cross section increases. A meaningful comparison can only be made for ribbons of equal thickness. At constant ribbon thickness, increasing the silicon content significantly reduced the bend ductility.

Ribbons with silicon compositions near $6.5 \mathrm{wt}$ pct and thickness greater than $50 \mu \mathrm{m}$ exhibited a large reduction in bend ductility. An interesting experiment using the Fe-6.4 wt pct Si samples employed electrolytic removal of material to reduce the ribbon thickness. Bend tests performed with an electrolytically thinned ribbon agreed well with $B_{n}$ values from the thinner as-solidified ribbons. Independent of microstructure, ribbon thickness influences the bend ductility because thinner ribbons would have a smaller mean free path with fewer impediments for dislocation glide to the free surface of the ribbon. Figure 7(b) shows the bend test data from the annealed $30-\mu \mathrm{m}$-thick Fe-6.4 wt pct $\mathrm{Si}$ ribbon (the same samples used for the DF images in Figure 5 and microhardness data in Figure 6(b)). For conditions where $\mathrm{B} 2$ and $\mathrm{DO}_{3}$ ordered structures were present, the bend ductility was reduced. The most severe brittle behavior was observed for annealing treatments at $400{ }^{\circ} \mathrm{C}$ and $500{ }^{\circ} \mathrm{C}$ for 24 hours, where microhardness was also affected. Although the microhardness after annealing at $600{ }^{\circ} \mathrm{C}$ is only slightly increased from the as-solidified state, the bend number has been reduced 


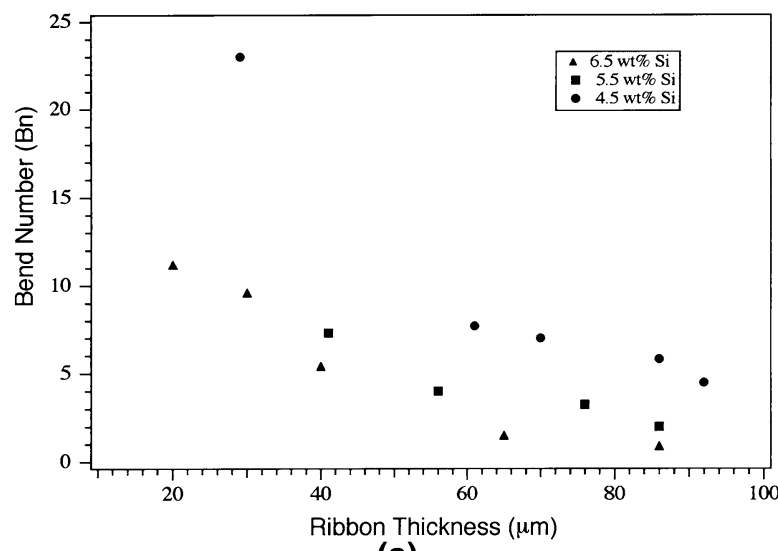

(a)

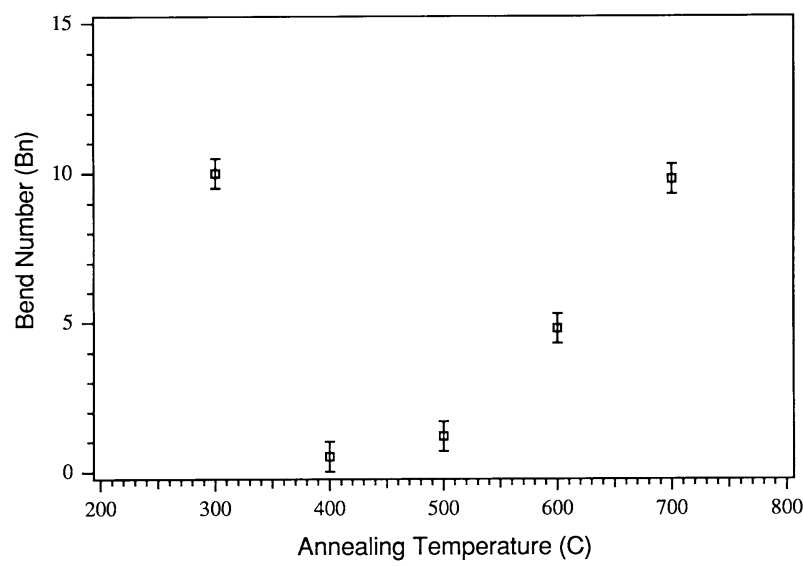

(b)

Fig. 7-(a) The bend test data for various silicon concentrations decrease as the ribbon thickness increases. Values of $B_{n}$ for individual ribbons were reproducible with variation in the bend number of \pm 0.5 or less. (b) Annealing a $30-\mu$ m-thick Fe-6.4 wt pct Si ribbon for $24 \mathrm{~h}$ at $400{ }^{\circ} \mathrm{C}$ or $500{ }^{\circ} \mathrm{C}$ reduces the bend ductility to where the sample fractured before it could be bent to a 90-deg angle.

from 10 down to 5. The DF images in Figures 5(e) and (f) show the mixture of $\mathrm{B} 2$ and $\mathrm{D}_{3}$ in the microstructure. Annealing at $700{ }^{\circ} \mathrm{C}$ results in a "B2" microstructure without $\mathrm{D}_{3}$ order and essentially the same microhardness and bend ductility as the as-solidified state where the microstructure consists of small B2 ordered domains as shown in Figure 5(a).

\section{F. Tensile Tests}

Figure 8 presents the data from uniaxial tensile tests of ribbons with various silicon compositions. Sample engineering stress-strain curves are shown in Figure 8(a). Figure 8(b) compares the yield stress and ultimate tensile stress for the 4.5, 5.5, and $6.4 \mathrm{wt} \mathrm{pct}$ silicon ribbons. Corresponding to the increase in microhardness with greater silicon content, as the silicon content increased from 4.5 to $6.4 \mathrm{wt}$ pct, the yield and tensile strength of the ribbons also increased. The fracture strain was strongly influenced by both composition and ribbon thickness. Similar to the bend test results, which show bend ductility for Fe-6.4 wt pet Si

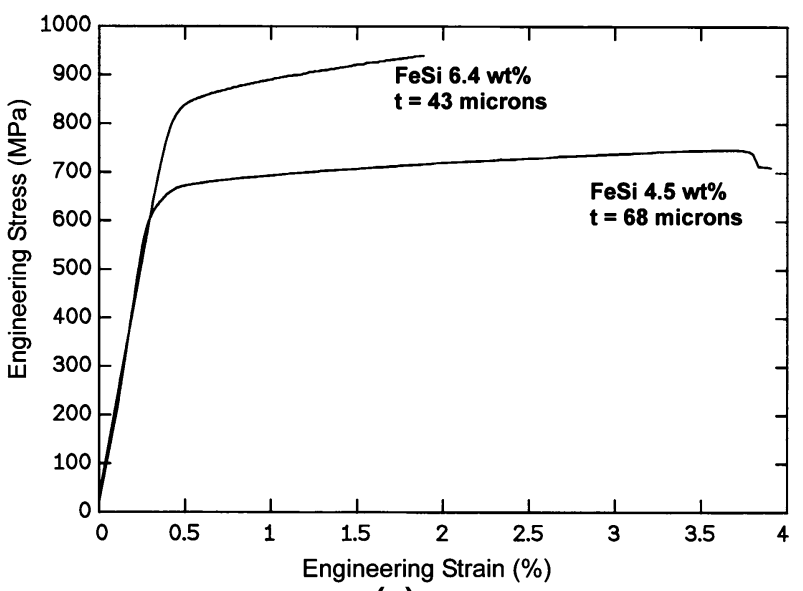

(a)

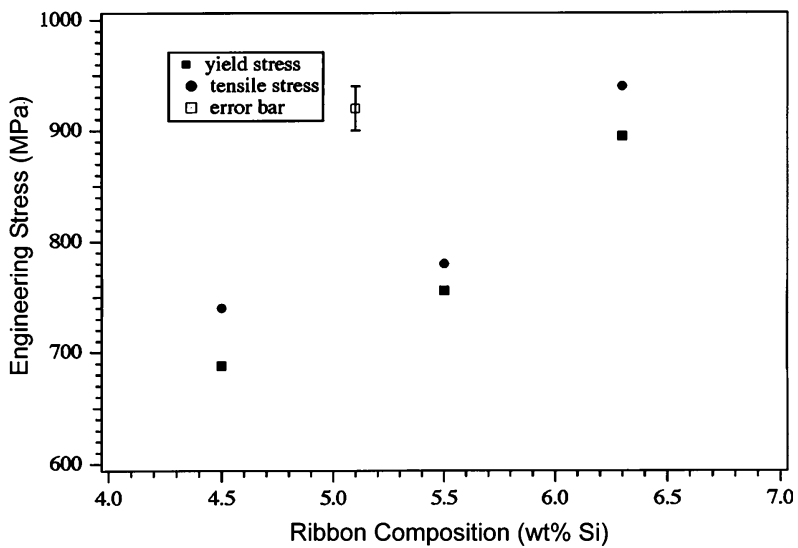

(b)

Fig. 8-(a) Typical engineering stress-strain diagrams for the Fe-4.5 and $6.4 \mathrm{wt}$ pet Si ribbons. (b) Both the yield stress and ultimate tensile stress increased with increasing silicon content.

ribbons with thickness less than $50 \mu \mathrm{m}$, the tensile data also reveal an analogous trend. For the Fe- 6.4 wt pet $\mathrm{Si}$ composition, a 30- $\mu \mathrm{m}$-thick ribbon exhibited over 2.25 pct elongation to failure, while the $43-\mu \mathrm{m}$ ribbon shown in Figure 8(a) has a maximum of 1.9 pct. Tensile tests of $65-$ and $86-\mu$ m-thick Fe-6.4 wt pct Si ribbons always exhibited fractured at stress levels well below the yield stress $\left(\sigma_{y} \sim 900 \mathrm{MPa}\right)$ without any plasticity. Similar brittle tensile behavior was observed for the annealed Fe-6.4 wt pct Si ribbons, which also exhibited no bend test ductility. For the most brittle annealed conditions (i.e., annealed at $400{ }^{\circ} \mathrm{C}$ or $500{ }^{\circ} \mathrm{C}$ for 24 hours), the Fe-6.4 wt pet Si material fractured before the sample could be tested. Reducing the silicon level increased the fracture strain and the maximum thickness for ductile behavior (e.g., stress-strain diagram for the Fe-4.5 wt pet $\mathrm{Si} 68-\mu \mathrm{m}$-thick ribbon in Figure 8(a) shows 3.8 pet elongation to failure).

\section{G. Fractography}

Bend test fracture surfaces, which result from a lowcycle fatigue test, are difficult to interpret compared to a 
simple uniaxial tensile test. It is interesting to note that although a Fe-6.4 wt pet $\mathrm{Si}$ ribbon with a $30-\mu \mathrm{m}$ thickness exhibits a $B_{n}=9.6$, the bend test fracture surface reveals only cleavage features. After bend testing, all of the Fe-6.4 wt pct Si ribbons fractured in a transgranular cleavage mode. In contrast, Figure 9(a) shows a secondary electron image of the fracture surfaces from a tensile sample of a $40-\mu \mathrm{m}$-thick Fe-6.4 wt pct Si ribbon that exhibited plasticity $\left(\varepsilon_{p l}=2\right.$ pct). Although this fracture surface revealed regions of necking with microvoid coalescence and dimpled rupture such as in Figure 9(a), some areas of brittle fracture were still always observed on the tensile fracture surfaces of the Fe- 6.4 wt pct $\mathrm{Si}$ ribbons. This mixed mode may be related to the fact that these ribbons have variations in thickness where thinner cross sections have increased stress levels. These areas would yield first and produce the localized ductile regions. Final fracture would occur in a transgranular cleavage mode. In contrast, fracture surfaces from tensile tests of the Fe-4.5 wt pct $\mathrm{Si}$ ribbons, which exhibited plastic flow, only show ductile fracture features. The Fe-5.5 wt pct Si samples were an intermediate case.

Examination of the fracture surfaces from $\mathrm{Fe}-6.4$ wt pct Si ribbons with thickness of more than $50 \mu \mathrm{m}$ helps to explain the change in ductile to brittle behavior as ribbon thickness is increased. These thicker Fe-6.4 wt pct $\mathrm{Si}$ ribbons always fractured at stress levels well below the yield stress for the material and displayed completely brittle fracture features. Figure 9(b) is typical of the cleavage fractures from the Fe-6.4 wt pet $\mathrm{Si}$ ribbons with thickness greater than $50 \mu \mathrm{m}$. However, in addition to the dominant transgranular fracture features, small areas of exposed dendrite arms were always observed tensile test fracture surfaces for thicker ribbons, as shown in Figure 9(c). These patches of dendrites are caused by solidification shrinkage and are equivalent to hot tearing in castings or welds. As ribbon thickness increases the magnitude of the solidification shrinkage stress increases. These dendrite features, which were consistently observed together with the cleavage features on both the bend test and tensile fracture surfaces of the thicker Fe-6.4 wt pct Si ribbons, were not seen on the fracture surfaces of the thinner ductile Fe-6.4 wt pet Si ribbons.

Tensile tests of the Fe- 6.4 wt pct $\mathrm{Si}$ ribbons annealed at $400{ }^{\circ} \mathrm{C}$ to $600{ }^{\circ} \mathrm{C}$ also fractured without yielding in a completely brittle mode, which often occurred before the tensile samples could be clamped into the testing machine. The fracture surfaces were always a mixed
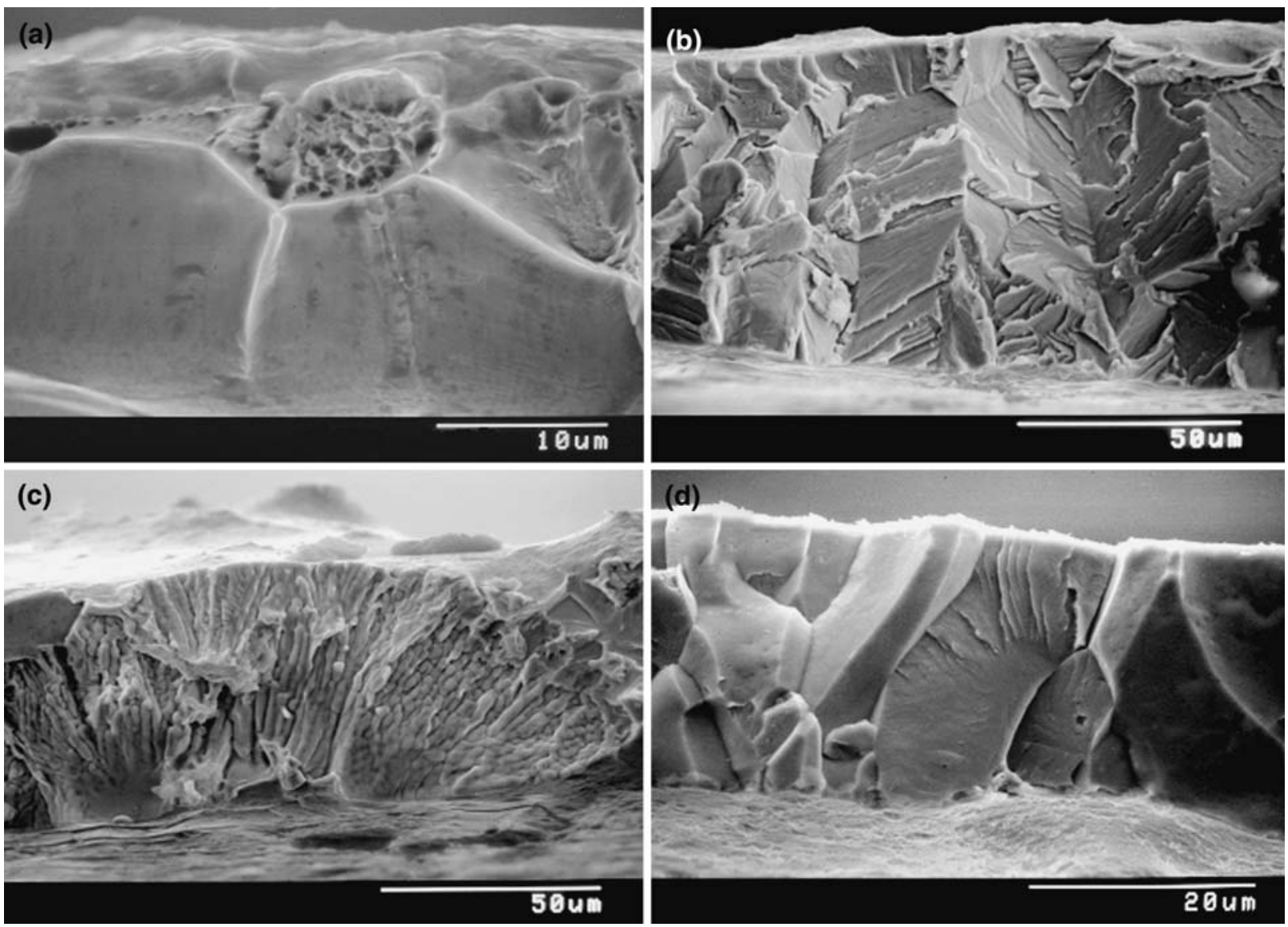

Fig. 9-Scanning electron micrographs of fracture surfaces from the Fe-6.4 wt pct Si ribbons tested in tension: (a) ductile fracture of a 40- $\mu \mathrm{m}-$ thick ribbon. (b) Brittle cleavage fracture of a 70- $\mu$ m-thick ribbon. (c) Dendrites caused by solidification shrinkage in a 60- $\mu$ m-thick ribbon. (d) Mixed intergranular and transgranular brittle fracture in a $30-\mu \mathrm{m}$-thick ribbon annealed at $500{ }^{\circ} \mathrm{C}$ for $24 \mathrm{~h}$. 
mode of intergranular decohesion and transgranular cleavage, as shown in Figure 9(d) for a 30- $\mu \mathrm{m}$ thick Fe-6.4 wt pet Si ribbon annealed at $500{ }^{\circ} \mathrm{C}$ for 24 hours. The AES was used to analyze the fracture surfaces by fracturing the annealed ribbons in an ultrahigh vacuum, but no chemistry differences were detected between the transgranular cleavage and the intergranular fracture paths. The AES data reveal no evidence for segregation of any impurities at the grain boundaries.

\section{H. Dislocation Configurations}

Melt-spun ribbon samples deformed in tension were prepared for TEM examination in order to investigate the influence of silicon concentration from 4.5 to $6.4 \mathrm{wt}$ pct on the dislocation configurations. Figures 10(a) and (b) show representative $\mathrm{BF}$ images of dislocations in deformed Fe-4.5 wt pet Si and Fe-6.4 wt pct Si tensile samples (both with plastic strain of about 2 pct). Consistent with previous reports, ${ }^{[18]}$ iron-silicon alloys with more than 4 wt pet $\mathrm{Si}$ exhibit planar slip. The inability for dislocation cross-slip may be responsible for this planar slip mode. This planar slip was observed in the deformed ribbons as long straight dislocations, which would often extend completely across the individual grain when the slip planes were appropriately aligned to the plane of the foil. The dislocation configurations after tension testing are in contrast to those observed in the ribbons after the melt spinning process. Typical dislocations in the as-solidified state exhibited curved morphologies with considerable line energy. These curved and occasionally tangled dislocations, which appear with a wide range of densities, were most likely produced at elevated temperatures after the hot ribbon left the melt spinning wheel.
Although the dislocations in the ribbons ranging in composition from 4.5 to $6.4 \mathrm{wt}$ pet $\mathrm{Si}$ have a similar morphology, the higher silicon content materials exhibited a larger concentration of planar dislocation lines before any cross-slip occurs. Qualitatively, the $6.4 \mathrm{wt}$ pct silicon materials showed a more pronounced planar slip mode than the ribbons with lower silicon concentration. The dislocations confined to the planar slip mode have either pure screw or edge character. For the Fe-6.4 wt pct Si ribbons, slip was most often observed on $\{112\}$ slip planes although $\{011\}$ and $\{123\}$ slip were also seen. The slip traces from 20 different grains showed 15 examples of $\{112\}$ slip with only three cases of $\{011\}$ and 2 of $\{123\}$ slip planes. This observation is consistent with that of Saburi and Nenno, ${ }^{[19]}$ but contradicts the findings of Barrett et al. ${ }^{[18]}$ where slip was restricted to $\{011\}$ planes at room temperature.

Dislocations in the deformed samples were frequently observed as pairs. Two beam images in Figures 11(a) and (b) formed using $+\mathbf{g}$ and $-\mathbf{g}$ diffraction vectors revealed that these pairs are often dislocation dipoles. This was especially the case for the Fe-4.5 and 5.5 wt pct $\mathrm{Si}$ alloy samples. However, in the Fe-6.4 wt pet $\mathrm{Si}$ ribbons, many of the dislocation pairs possessed the same Burgers vector as shown in Figures 11(c) and (d). These dislocation pairs were always more widely spaced compared with the dislocation dipoles. The nondipole pairs could be considered as a superlattice dislocation in a B2 ordered structure. However, this terminology would be difficult to apply for a $6.4 \mathrm{wt}$ pct $\quad(\sim 12$ at. pct) silicon sample, which is stoichiometric deficient for B2 order, and for the rapidly solidified materials in this study, where the ordered phase transformation is significantly incomplete as shown by the B2 DF image in Figure 5(a).
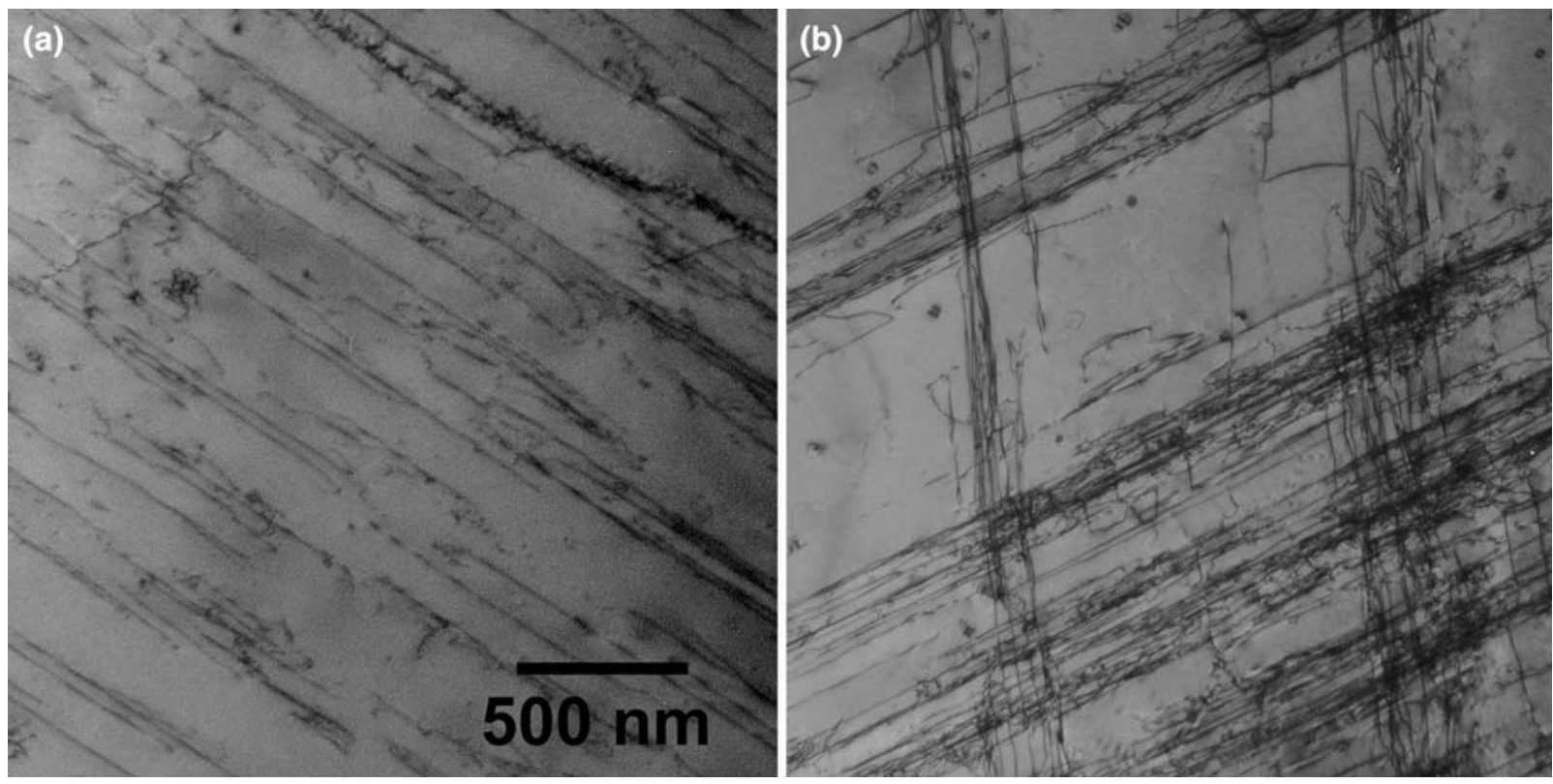

Fig. 10-The BF images show the dislocation configurations for $(a)$ the Fe-4.5 wt pct Si material and $(b)$ the Fe- 6.4 wt pct Si ribbon after tensile deformation $(\varepsilon \sim 2 \mathrm{pct})$. 

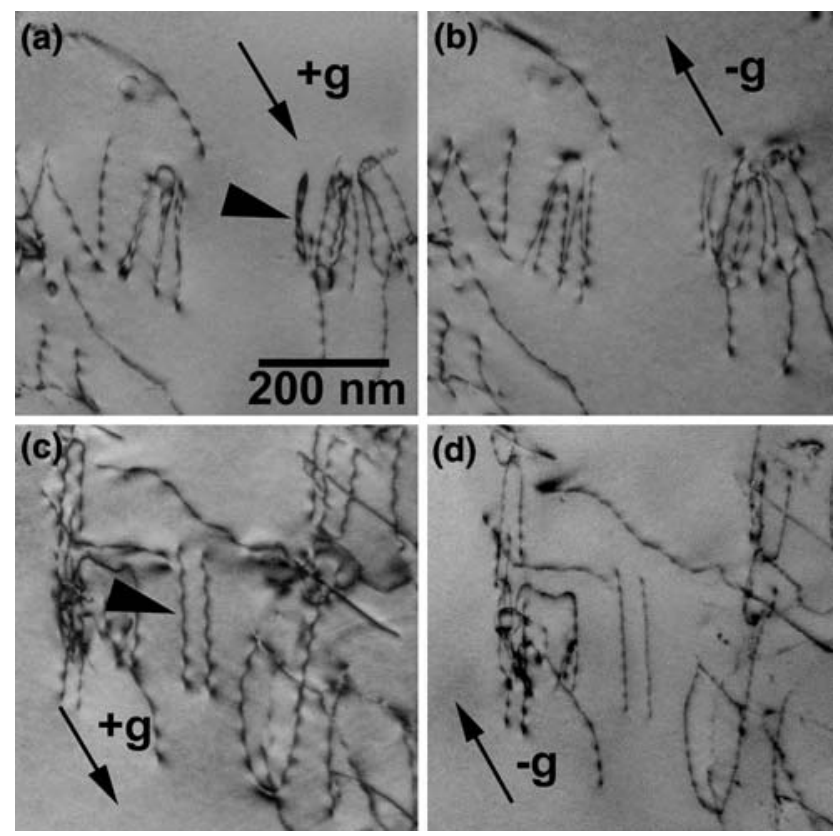

Fig. 11-These pairs of BF images using the diffraction condition with $\pm \mathbf{g}=\{110\}$ of the deformed Fe-6.4 wt pct Si ribbons show both $(a)$ and $(b)$ dislocation dipoles and $(c)$ and $(d)$ dislocations with identical Burgers vectors. Examples of dipoles and superlattice dislocations are indicated with arrowheads in the images.

\section{DISCUSSION}

\section{A. Chemical Ordering in Iron-Silicon}

Microhardness data in Figures 6(a) and (b) and tensile properties in Figures 8(a) and (b) reveal the enormous influence that silicon composition from 4.5 to $6.4 \mathrm{wt}$ pct, has on the critical resolved shear stress required for dislocation slip in iron-silicon solid solutions. Because microstructural parameters, such as grain size and dislocation density, have remained relatively constant in these melt-spun ribbons, one must consider the substitutional solid-solution hardening effect of silicon on the mechanical properties. Silicon is accommodated substitutionally in the iron lattice owing to a size difference of only about 6 pct and identical Pauling's electronegativities of 1.8. However, the different electron configurations of iron and silicon, specifically the strong $\mathrm{p}$-d electron interactions of $\mathrm{Si}$ and Fe atoms, which result in a greater contribution to covalent bonding, and different equilibrium crystal structures, account for the tendency to form long-range order as silicon content increases.

As previously discussed, the thermodynamical stability of the $\mathrm{B} 2$ and $\mathrm{D}_{3}$ superlattices in iron-silicon alloys indicates that the bond energy of the silicon-iron bond is less than one half the bond energy of a silicon-silicon bond plus an iron-iron bond in the bcc lattice. This increased bond energy can be appreciated after considering that the highly directional silicon-silicon bond angle, which is rigidly fixed at $109.5 \mathrm{deg}$ in the diamond cubic structure, must conform to the bcc bond angle of $70.5 \mathrm{deg}$. The resulting disruption in the electronic structure of the iron lattice by silicon is clearly revealed by the steep increase in electrical resistivity with increasing silicon content. The increase in bond energy from silicon-silicon interaction has long-range influence. Thus, silicon atoms attempt to minimize both first and second nearest silicon neighbors by forming the $\mathrm{D}_{3}$ superlattice where both first and second nearest neighbors are iron.

The energetically unfavorable silicon-silicon bond in the bcc iron lattice leads to superlattice formation. A great deal of effort has been directed toward understanding the phase equilibria for this binary system. The A2 to B2 transformation is considered to be of the second order where the ordering progresses in a continuous mode in contrast to a nucleation and growth mechanism. Therefore, what does the B2 phase boundary that occurs at a minimum silicon level of about $5 \mathrm{wt}$ pct represent? As silicon content increases, the mutual repulsion of silicon atoms in a bcc structure reaches a level where long-range interactions are adequate to cause the (002) planes to alternate between silicon rich ones and silicon depleted ones, thereby changing the structure factor sufficiently to be detected in an electron diffraction experiment. Diffusion of silicon of only one atomic jump would be required to produce this arrangement. However, at 10 at. pct silicon, only one out of every five silicon B2 superlattice points has a correct atom with the other $80 \mathrm{pct}$ of the silicon superlattice sites occupied by iron atoms. The label B2 could be considered as a misnomer since the only real similarity is the presence of the B2-type superlattice diffraction spots. In fact, at 50 at. pct silicon, the stable phase is the epsilon phase with a B20 cubic structure.

One can perhaps better refer to the transition from the disordered region of the binary phase diagram to the B2 phase boundary with increasing silicon concentration, as a precursor for the $\mathrm{D}_{3}$ phase or simply disordered $\mathrm{D} 0_{3}$. At somewhat higher silicon concentration, a two-phase region exists at temperatures below the Curie temperature with both $\mathrm{B} 2$ and $\mathrm{D}_{3}$ phases in equilibrium. The $\mathrm{B} 2$ to $\mathrm{D}_{3}$ phase transition has been shown to be first order. Along the lines of the above discussion, this miscibility gap can perhaps be better viewed as a twophase ordered $\mathrm{D}_{3}$ - disordered $\mathrm{D} 0_{3}$ region where there are inadequate silicon atoms to create the interaction required to form a complete $\mathrm{D}_{3}$ symmetrical arrangement. In other words, as the number of silicon atoms increases so that each atom is being influenced by the long-range affect of increased bond energy of siliconsilicon bonds, $\mathrm{D}_{3}$ symmetry is produced.

\section{B. Influence of Silicon on Slip in bcc Iron}

The important aspect of the chemical ordering of iron and silicon atoms for this discussion is the influence of the silicon atomic distribution in the iron lattice on dislocation slip. In addition to an increased Peierls stress from elastic strain in the lattice, the influence on the stress required to move a dislocation from the increase in free energy due to the silicon-silicon interaction must also be considered. If even in the disordered state, the silicon atoms in these relatively dilute alloys are positioned so as to minimize their interactions (i.e., no 
silicon-silicon nearest neighbors) dislocation slip will inevitably bring some silicon atoms into closer proximity. As the silicon level increases, the probability that a dislocation will result in silicon-silicon nearest neighbors will increase accordingly. Cross-slip would also be inhibited by the same energetic considerations.

The rapidly solidified ribbons produced for this investigation offer the opportunity to study the effect of the perfection of chemical order on the mechanical properties. The rapidly solidifed ribbons with $6.4 \mathrm{wt}$ pct silicon exhibited a large variation in the amount of B2 order (area fractions in a DF image such as in Figure 5(a)) as a function of cooling rate and ribbon thickness. However, the microhardness levels were relatively constant for all of the as-solidified B2 domain distributions. An explanation for this behavior relates back to the meaning of a DF image in these nonstoichiometric ordered alloys. Regions, which contain enough chemical order of the atoms to adjust the structure factor adequately to form a superlattice diffraction spot, will appear bright in a DF image. Because the ribbons are still relatively disordered, the differences required to affect the structure factor do not strongly influence the shear stress for slip. The probability for a dislocation to cause two silicon atoms to come into intimate contact is similar for either a disordered or an ordered structure. This would also account for the occurrence of pairs of dislocations with the same Burgers vector in the relatively disordered Fe-6.4 wt pet Si melt-spun ribbons after tensile tests. As reported by Nenno and Sabori, superlattice dislocations occur in the ordered iron-silicon alloys. ${ }^{[13]}$ Although the rapidly solidified ribbons are not fully ordered, superlattice dislocations would also decrease the energy of the system by removing any new siliconsilicon bonds by the passage of a second dislocation with an $\mathbf{a} / 2\langle 111\rangle$ Burgers vector. Cross-slip would be retarded by the lower energy configuration for deformation of pairs of ordinary dislocations moving through the lattice.

Annealing the $\mathrm{Fe}-6.4 \mathrm{wt}$ pct $\mathrm{Si}$ ribbons at temperatures that promote further $\mathrm{B} 2$ and $\mathrm{D}_{3}$ order only revealed subtle changes in hardness compared to the much more pronounced affect of increasing silicon concentration. Significant changes in the microhardness only occurred for the Fe-6.4 wt pet Si ribbons after annealing at $400{ }^{\circ} \mathrm{C}$ or $500{ }^{\circ} \mathrm{C}$ for 24 hours, although this increase is small and just slightly greater than the scatter in the microhardness measurements. For the 6.4 wt pet alloy, the two-phase $\mathrm{B} 2$ and $\mathrm{D}_{3}$ microstructure with quite small domains in Figure 5(c) and (d) results in an increased microhardness. If a miscibility gap actually exists in this system, there may be a variation in the silicon concentration on a localized level. Then the hardness increase could be attributed to the average hardness for the two phases. Another explanation could be the affect of APBs on the critical shear stress for slip. The large numbers of APBs present after heat treatments at $400{ }^{\circ} \mathrm{C}$ and $500{ }^{\circ} \mathrm{C}$ heat treatments could also be responsible for the increase in the microhardness from 480 to $520 \mathrm{HV}$. An interesting observation is that after annealing at $600{ }^{\circ} \mathrm{C}$ for
24 hours where the structure is two-phase $\mathrm{B} 2$ and $\mathrm{D} 0_{3}$, the microhardness is virtually equal to the initial as-solidified state. The same situation holds for the $700{ }^{\circ} \mathrm{C}$ annealing treatment where the structure is completely B2 but the hardness is again unchanged from the relatively disordered initial state.

\section{Plasticity and Fracture}

The effect of ribbon thickness on the ductility of Fe-6.4 wt pct $\mathrm{Si}$ ribbons is one that needs to be addressed. The bend tests (i.e., low-cycle fatigue tests) can only be used to compare ribbons of the same thickness for obvious reasons. This was demonstrated for ribbons with $6.4 \mathrm{wt}$ pct silicon that were reduced in cross section by electrochemical thinning. As expected, because the composition and microstructures were the same, the bend test data were similar for a constant thickness. However, the thicker Fe-6.4 wt pct Si ribbons were brittle and the thin ribbons were ductile for both bend tests and the tensile tests. A number of factors must be considered to explain this behavior. First, thinner ribbons offer a reduced mean free path of gliding dislocations with fewer impediments to slip before they can reach the surface. The attractive surface image force would promote dislocations to slip out of the ribbon and remove strain hardening effects. Thicker ribbons would show stronger effects of dislocation interaction from lack of cross-slip and therefore strain hardening would be enhanced. In addition, the thicker ribbons have a greater propensity to form shrinkage cracks that act as stress intensification points causing premature fracture at stresses far below that for the critical shear stress for dislocation slip.

The change in fracture mode of the ribbons with increasing silicon concentration can be related to the classic work by Barret et al. ${ }^{[18]}$ on the fracture behavior of bulk iron-silicon alloys. The abnormal transition from wavy to planar slip was found to occur at approximately the same composition as the ductile to brittle transition. ${ }^{[18]}$ The increased stress required for slip and the inability for dislocations to cross-slip is directly dependent upon the silicon composition as described above. One can use a simplistic model to relate the characteristic brittleness of iron-silicon alloys to the relative values of interplanar cohesion, intergranular cohesion, and slip resistance. The brittle fracture mode is mainly cleavage along $\{100\}$ planes, which occurs when the normal stress across the cleavage planes surmounts the cohesive strength of the lattice, before the shear stress activates adequate slip to accommodate the deformation. It is the relatively larger increases in the stress required to overcome slip resistance at the onset of deformation with increasing silicon levels compared to the smaller increase, or perhaps decrease, in the cohesive interplanar stress at room temperature that accounts for the brittle behavior.

Comparison of the microhardness data and the bend test fracture behavior of the annealed ribbons with Fe-6.4 wt pct Si ( $t=28 \mu \mathrm{m}$ in thickness) reveals the influence, or lack of influence, of chemical ordering on deformation and fracture. After the $400{ }^{\circ} \mathrm{C}$ and $500{ }^{\circ} \mathrm{C}$ 
for 24 hours heat treatments, the Vickers microhardness increased from about 385 to $420 \mathrm{HV}$, the bend number decreased from ten to less than one, and the fracture mode changed from transgranular cleavage to a combination of intergranular and cleavage. The brittleness increased owing to a larger stress required for slip compared to the reduced critical stress for intergranualar and interplanar decohesion. The intergranular fracture mode can also be attributed to the favorable orientation of the grain boundaries to the tensile stress from the bending mode. The microstructure exists as a fine dispersion of $\mathrm{B} 2$ and $\mathrm{D}_{3}$ ordered domains.

However, heat treatment at $600{ }^{\circ} \mathrm{C}$ results in an equilibrium two-phase $\mathrm{B} 2$ and $\mathrm{D}_{3}$ ordered microstructure that exhibited a microhardness of $400 \mathrm{HV}$, almost unchanged from the as-solidified level, and the bend number decreased from ten to an intermediate value of about four. The fracture mode is mostly cleavage with little evidence of grain boundary decohesion. While similar microhardness to the as-solidified material suggests that the stress for slip is not significantly affected, the reduced bend number indicates that the stress for interplanar decohesion is decreased from the partially ordered state to the equilibrium ordered state. Finally, annealing at $700{ }^{\circ} \mathrm{C}$, which results in a completely B2 ordered microstructure with no visual evidence of $\mathrm{D}_{3}$ domains in the DF images, exhibits identical microhardness, bend ductility, and fracture features as the as-solidified ribbons. The combination of $\mathrm{B} 2$ and $\mathrm{D}_{3}$ order is clearly more detrimental to the mechanical properties than the presence of $\mathrm{B} 2$ order alone.

\section{CONCLUSIONS}

The mechanical properties, specifically the deformation and fracture behavior of rapidly solidified and annealed iron-silicon melt spun ribbons with 20 to 120 $\mu \mathrm{m}$ in thickness and silicon contents ranging from 4.5 to $6.4 \mathrm{wt}$ pct were investigated in view of their microstructural features, preferred crystal orientation (texture), dislocation configurations, and $\mathrm{B} 2 / \mathrm{DO}_{3}$ ordering.

1. Increasing the silicon content from 4.5 to $6.4 \mathrm{wt}$ pct has an enormous influence on the mechanical properties of the as-solidified melt-spun ribbons. Hardness increased by 40 pct, the yield stress increased from 690 to $900 \mathrm{MPa}$, and ductility is drastically reduced. These changes in mechanical properties are caused by the solid solution hardening of silicon in the iron lattice, the reduction in dislocation cross-slip at higher silicon levels resulting in planar slip mainly on $\{112\}$ planes, and increased chemical order that produces superlattice dislocation formation.

2. Thinner ribbons exhibit greater ductility than the thicker ribbons owing to a plane strain condition where the free surface promotes dislocation mobility with a reduced mean free path and fewer impediments to glide before dislocations reach the ribbon surface. The attracting surface image force promotes dislocations to slip out of the ribbons and removes strain hardening effects. The influence of dendritic features on the fracture path of the thicker ribbons from solidification shrinkage also reduces the ductility.

3. The coexistence of nanometer size $\mathrm{B} 2$ and $\mathrm{DO}_{3}$ ordered domains within the microstructure of the Fe-6.4 wt pet Si ribbons heat treated at $400{ }^{\circ} \mathrm{C}$ and $500{ }^{\circ} \mathrm{C}$ causes the largest hardness increase and most brittle behavior owing to a large number of APBs that are obstacles for $\mathbf{a} / 2$ [111] dislocation glide. The presence of single-phase "B2" is not so detrimental to the mechanical properties as the combination of $\mathrm{B} 2$ and $\mathrm{D}_{3}$.

\section{ACKNOWLEDGMENTS}

The authors acknowledge the numerous contributions of Dr. Erhardt Vogt and Manfred Kreuss in the performance of these experiments. J. Wittig personally appreciates the valuable assistance from Ms. Erika Bartsch with the TEM aspects of this work. This research was funded by the German Science Foundation.

\section{REFERENCES}

1. R.M. Bozoth: Ferromagnetism, Van Norstrand, New York, NY, 1951.

2. K. Gunther, G. Abbruzzese, S. Fortunati, and G. Ligi: Proc. Soft Magnetic Materials 16th Conf., Düsseldorf, Germany, Sept. 2003, German Steel Institute, 2003, pp. 41-50.

3. E.S. Greiner: The Alloys of Iron and Silicon, McGraw-Hill, New York, NY, 1933.

4. G. Schlatte and W. Pitsch: Z. Metallkd., 1975, vol. 66 H.11, pp. 660-68.

5. D. Ruiz, T. Ros-Yañez, L. Vandenbossche, L. Dupré, R.E. Vandenberghe, and Y. Houbaert: J. Magn. Magn. Mater., 2005, vols. 290-291, pp. 1423-26.

6. D. Ruiz, T. Ros-Yañez, L. Ortega, L. Sastre, L. Vandenbossche, B. Legendre, L. Dupre, R.E. Vandenberghe, and Y. Houbaert: IEEE Trans. Magn., 2005, vol. 41, pp. 3286-88.

7. T. Ros, D. Ruiz, Y. Houbaert, and R.E. Vandenberghe: J. Magn. Magn. Mater., 2002, vols. 242-245, pp. 208-11.

8. D. Ruiz, T. Ros-Yañez, E. DeGrave, R.E. Vandenberghe, and Y. Houbaert: J. Magn. Magn. Mater., 2004, vols. 272-276, pp. e1663-e1665.

9. D. Ruiz, T. Ros-Yañez, G.J. Cuello, R.E. Vandenberghe, and Y. Houbeart: Physica B, 2006, vols. 385-386, pp. 578-80.

10. P.A. Flinn: Trans. AIME, 1960 , vol. 218 , p. 145.

11. M.J. Marcinkowski and R.M. Fisher: J. Appl. Phys., 1963, vol. 34, pp. $2135-45$.

12. J.S. Koehler and F. Seitz: J. Appl Mech, 1947, vol. 14, pp. A21724.

13. M.J. Marcinkowski and N. Brown: Acta Metall., 1961, vol. 9, pp. 764-86.

14. M.J. Marcinkowski, N. Brown, and R.M. Fisher: Acta Metall., 1961, vol. 9, pp. 129-37.

15. M.J. Marcinkowski and L. Zwell: Acta Metall., 1963, vol. 11, pp. 373-90.

16. W. Schröer, C. Hartig, and H. Mecking: Z. Metallkd., 1993, vol. 84 (5), pp. 294-300.

17. M.G. Mendiratta, S.K. Ehlers, D.K. Chatterjee, and H.A. Lipsitt: Metall. Trans. A, 1987, vol. 18A, pp. 283-91.

18. C.S. Barrett, G. Ansel, and R.F. Mehl: Trans. ASM, 1937, vol. 25, pp. $702-36$. 
19. T. Saburi and S. Nenno: Philos. Mag, 1967, vol. 15, pp. 813-24.

20. M.J. Tenwick and H.A. Davies: Int. J. Rapid Solidification, 1984 85, vol. 1, pp. 143-55.

21. K. Raviprasad, M. Tenwick, H.A. Davies, and K. Chattopadhyay: Scripta Mater., 1986, vol. 20, pp. 1265-70.

22. Y. Sato, T. Sato, and Y. Okazaki: Mater. Sci. Eng., 1988, vol. 99, pp. 73-76.
23. E. Vogt, G. Frommeyer, J.E. Wittig, and H. Sassik: Mater. Sci. Eng., 1988, vol. 98, pp. 295-99.

24. H. Seifert, M. Jurisch, J. Tobisch, and C.G. Oertel: Mater. Sci. Eng. A, 1991, vol. 133, pp. 292-96. 